\title{
The dolphin's grammatical competency: Comments on Kako (1999)
}

\author{
LOUIS M. HERMAN and ROBERT K. UYEYAMA \\ University of Hawaii, Honolulu, Hawaii
}

\begin{abstract}
Kako (1999) reviews the evidence for syntactic competencies in several animal species exposed to artificial language systems, emphasizing the importance of core syntactic properties such as argument structure and closed-class items. We present evidence from our dolphin studies for the acquisition of the closed-class functionality of demonstratives, prepositions, conjunctions, and locatives. Sensitivity to argument structure is also evidenced by wholly untrained and consistent interpretations of the dolphin to probes of anomalous syntactic structures. These results are generated within our comprehension-based paradigm, which enables us to provide convincing objective evidence for the development and generalization of concepts by the dolphin subject. Demonstrations of animal language competencies may illuminate certain aspects of human linguistic competence by suggesting that the particular modeled subsets can derive from general cognitive mechanisms, rather than language-specific ones.
\end{abstract}

The ability of language-trained animals to demonstrate syntactic competency has a long history of controversy. Kako (1999) attempts to clarify and focus the issue by (1) restricting the discussion to certain core properties of syntax and (2) summarizing experimental evidence showing competencies for processing of these properties by language-trained chimpanzees, dolphins, and a parrot. Our comments focus on the evidence for dolphins, particularly their knowledge of the grammatical structure of the languages taught them, including their responses to a variety of closed-class items. Kako emphasizes closedclass items as an important area of investigation for evaluating animal language syntactic competencies but was not aware of any data in this area, which we now provide.

First, however, we would like to emphasize that the convincing evidence for syntactic processing abilities by animals, as well as the evidence for semantic processing, has come primarily from studies of language comprehension rather than language production (see, e.g., the review in Herman, 1987). The language work with dolphins emphasized comprehension from its start (ca. 1975) and represented a marked departure from existing approaches to studies of animal language competencies (see Herman, 1980; Herman, Richards, \& Wolz, 1984). At that early time, the prior and ongoing animal language studies were focused on language production (e.g., Gardner \& Gardner, 1971; Patterson, 1978; Rumbaugh 1977; cf. Premack, 1976). These early studies gave relatively little consideration to receptive competencies, sometimes assuming (falsely) that comprehension flowed automatically from production (see Savage-Rumbaugh, Rumbaugh, \& Boysen, 1980). For example, the Gardners

Correspondence concerning this article should be addressed to L. M. Herman, Kewalo Basin Marine Mammal Laboratory, 1129 Ala Moana Blvd., Honolulu, HI 96814 (e-mail: Iherman@hawaii.edu).
(Gardner \& Gardner, 1975) disavowed the importance of formally assessing and documenting the receptive competency of their chimpanzee subject Washoe, simply stating, instead, that her receptive vocabulary was extensive. The need to document comprehension should have been anticipated perhaps, given the evidence of marked differences in language production and comprehension emerging from child language studies; for example, children have been shown to produce sentences of a certain structure without comprehending their meaning (see, e.g., Fraser, Beluggi, \& Brown 1963; also see Herman \& MorrelSamuels, 1990).

The comprehension strategy we adopted for the dolphins derived from both theoretical and pragmatic considerations. In practical terms, unlike the case for apes, there was no easily instrumented means for symbol production by dolphins (see, e.g., Richards, Wolz, \& Herman, 1984). More important, however, the comprehension approach used with the dolphins afforded greater control over stimuli and context than is available with language production; through the use of imperative sentences constructed within the languages taught, the dolphins' understanding of the imperatives could be measured by the accuracy and reliability of their responses, including responses to novel sentence content and structure (for details, see Herman et al., 1984). The objectivity, replicability, quantification, and freedom from observer biases available through this comprehension approach were essentials, given the Zeitgeist in which criticisms of the lack of these elements in the ape language studies were escalating strongly (e.g., Petitto \& Seidenberg, 1979; Ristau \& Robbins, 1982; Terrace, Petitto, Sanders, \& Bever, 1979; Thompson \& Church, 1980).

The emphasis on a comprehension approach was also driven by findings from human language acquisition studies showing, for example: the generally early emergence of language comprehension skills in children rel- 
ative to language production (e.g., Ingram 1989; see, also, summaries in Bates, 1993); the continued superiority of comprehension in adults (Ingram, 1989); the advantages of tests of comprehension for assessing grammatical competencies of young children (see, e.g., Strohner \& Nelson, 1974); and the utility of the comprehension approach for teaching second languages (Winitz, 1981). ${ }^{1}$ The recent successes of Savage-Rumbaugh and her colleagues in demonstrating reliable syntactic competencies in bonobos primarily derives from those aspects of their work that follow the comprehension approach we adopted (Savage-Rumbaugh et al., 1993; Sevcik \& SavageRumbaugh, 1994).

Returning, then, to Kako's (1999) discussion of syntactic competencies, we comment on argument structure and closed-class items.

\section{Argument Structure}

Kako (1999) discusses the responses of the dolphin Akeakamai (Ake), trained in a gestural language, to anomalous strings of gestures (Herman, Kuczaj, \& Holder, 1993; Holder, Herman, \& Kuczaj, 1993). He notes that Ake sometimes rejected an anomaly, and sometimes repaired the anomaly by carrying out a response to a grammatically correct subset of items contained within the overall string. But he then says that "it's not obvious what else Ake could have done ... besides reject or repair ..." (p. 9). Actually, she could also have carried out irrelevancies or created agrammatic responses, but these almost never occurred. Contrary to Kako's interpretation, the strategies of reject or repair were not chosen randomly or inconsistently but were applied in specific ways. These strategies were not taught but were entirely of Ake's own making. Anomalous strings occurred at a very low rate (two per 19-trial session), and her responses to these were neither reinforced nor punished, obviating any possibility of influencing her strategies during the course of testing. Her responses to these novel forms were thus conceptual leaps, transcending any specific learning.

Repair is a complex strategy in that it requires active processing of the semantic and structural components of the anomaly in order to extract a grammatical subset. For example, Kako (1999) discusses the responses of Ake to anomalous relational strings consisting of extraneous arguments, such as an extra destination (D) object or an extra transport (T) object. ${ }^{2}$ Ake's responses to these anomalies offer some of the strongest support for her grammatical knowledge. Consider, for example, the anomalous string $D T_{1} T_{2} R$, consisting of a destination object, two transport objects, and a relational verb (FETCH or IN/ON). An example is PHOENIX HOOP FRISBEE FETCH. The overall string is anomalous in that there is no grammatical form in Ake's taught language that has three object names.

However, embedded within this anomalous form are three grammatical subsets, $\mathrm{DT}_{1} \mathrm{R}, \mathrm{DT}_{2} \mathrm{R}$, and $\mathrm{T}_{1} \mathrm{~T}_{2} \mathrm{R}$.
Ake's typical response was to organize and carry out a response to one of these subsets, sometimes choosing one type and sometimes choosing another. Extraction of a subset required that Ake analyze the entire string, generally forward and backward, to seek a syntactically correct sequence that was executable. In some cases, this resulted in conjoining nonadjacent items (e.g., the subset $\mathrm{DT}_{2} \mathrm{R}$ ). This dual type of processing, selectively rejecting or repairing, is a more sophisticated response than simply choosing to reject all anomalous strings. Rejection was also virtually nonexistent for new grammatical structures that logically extended existing ones (Herman et al., 1984). Rejection did occur for anomalous strings in which semantically and/or syntactically correct sequences could not be extracted. These anomalous types typically involved a request to transport a nontransportable object. For example, the sequence $D_{1} D_{2} R$, such as WATER SPEAKER IN, asks that Ake place one nontransportable object (the underwater speaker) on top of another nontransportable object (the stream of water entering the tank). Ake rejected five of six semantic anomalies of this type (Holder et al., 1993).

Also, most tellingly, Ake never resorted to forms of repair that were agrammatic. For example, anomalies of the type TDR (e.g., BASKET SPEAKER FETCH) requested Ake to transport a nontransportable object to a transportable object. That Ake never attempted to reverse the sequence to create DTR illustrates that the word order rules and the relation of thematic role to word order were firmly incorporated into Ake's concepts of the grammar of the language, strongly suggesting knowledge of argument number. Overall, this set of findings underscores the robustness of comprehension by Ake of her learned language, in that to repair an anomaly appropriately (e.g., $\mathrm{DT}_{1} \mathrm{~T}_{2} \mathrm{R} \rightarrow \mathrm{DT}_{2} \mathrm{R}$ ) or reject it appropriately (e.g., $D_{1} D_{2} R \rightarrow$ reject) required an understanding of grammatical and semantic relations and of pragmatic issues deriving from the link between thematic role and syntactic position. ${ }^{3}$

\section{Closed-Class Items}

Kako (1999) places special emphasis on closed-class items for the evaluation of syntactic processing competencies of the language-trained animals. Closed-class items (function words as opposed to content words) include language elements that constitute a closed set, such as prepositions. Function words serve primarily to define the grammatical relationships between content words. Kako states that an understanding of closed-class items has not yet been investigated in any of the animal language work. However, there is evidence in the dolphin language work for an understanding of demonstratives, prepositions, a conjunction, and locatives-all function words.

The demonstrative. Herman, Pack, and MorrelSamuels (1993) described a dolphin's understanding of a human's indicative (pointing) gesture that was directed toward a remote object. The point, when followed by an ac- 
tion gesture, directed the dolphin Phoenix to perform that action to that object. ${ }^{4}$ The indicative gesture, in the context described, is a reference to an object lying in the direction in which the signer has pointed and, in effect, functions like the demonstrative that. It is intriguing that dolphins, unlike other nonhuman animals, including chimpanzees (see, e.g., Povinelli \& Davis, 1994; SavageRumbaugh, 1986), appear to easily understand the significance of the human outstretched hand and finger. Possibly, this understanding is a generalization from the directionality of their "searchlight beam" echolocation signal which "illuminates" remote objects sonically, a behavior also associated with a linear posture of the rostrum pointing at the echolocated object. It has been recently demonstrated, for example, that one dolphin can identify the target being sonically illuminated by another dolphin (Xitco \& Roitblat, 1996).

To test Phoenix's understanding of the indicative gesture, three objects were arrayed along the perimeter of the dolphin's tank, forming the vertices of an equilateral triangle. Phoenix was positioned next to a signer, who was on a surfboard in the middle of the tank. Following a preplanned, balanced schedule, the signer pointed in the direction of an object for approximately $1-2 \mathrm{sec}$ and then signed the action term OVER. Phoenix responded appropriately in 17 of 21 cases, by swimming to the indicated object and leaping over it. Further probe tests, in which no object was positioned in the direction of the indicative gesture, showed that Phoenix was not simply swimming in the indicated direction but, instead, understood that the gesture referenced an object (i.e., the gesture functioned like the deictic pronoun that). In these missing object cases, Phoenix started in the indicated direction but then quickly diverted from that path and, instead, approached one of the remaining two objects and carried out the required action to that object.

We recently extended this test to see whether Phoenix might understand a sequence of indicative gestures. Three objects-a hoop, a surfboard, and a basket-were positioned left, behind, and right of Phoenix as she faced her trainer. The trainer, who was positioned outside the tank wall, pointed to one of the three objects briefly, then gave the gestural sign for FETCH, and then pointed briefly to one of the two remaining objects. The intent of this sequence, which can be glossed as THAT FETCH THAT, was to direct Phoenix to bring the first referenced object to the second. Note that Phoenix cannot simply follow the directional points in real time but must make a further choice of destination once the first object is acquired. Hence, she must create a mental representation of the requested relationship that preserves the information given her at the beginning of the trial.

The probability of a correct response by chance alone is $1 / 6(1 / 3 \times 1 / 2)$. Three blocks of 18 trials each were run, each block containing 6 FETCH trials interleaved among 12 simple indicative trials. The latter consisted of a brief pointing gesture toward an object, followed by a sym- bolic gesture for an action, as in the earlier described study with Phoenix. Each of the 6 FETCH trials within a block was unique (e.g., take the left object to the center object, take the center object to the left object, etc.), and each block was a unique arrangement of the three objects (left, behind, and right). Of the total of 18 THAT FETCH THAT trials, Phoenix was wholly correct on 9 , taking the first indicated object to the second $(p<.002$ by summed binomial test). Also, she was correct on $32(88.9 \%)$ of the 36 simple indicative trials $(p<.01)$. Clearly, Phoenix's understanding of the indicative gesture is profound, even when used in the novel context of taking one indicated object to another.

The preposition. Prepositions coding the notions by or in were not explicitly taught to either dolphin but were implicit within the relational sentences given them. Linguistically, the absence of explicit prepositions occurs commonly in the simplified grammar of pidgin languages, as well as in "telegraphese," with little or no loss of understanding. Telegraphic speech characterizes the early speech of some young children, in which sentences consist of combinations of content words without function words (see, e.g., Bloom, Lightbrown, \& Hood, 1975).

In Ake's language, the sequence DTR requires Ake to construct a relation between two named objects by taking the $T$ object to the side of the $D$ object $(R=$ FETCH $)$ or by placing the $T$ object on top of or inside of the $\mathrm{D}$ object $(\mathrm{R}=\mathrm{IN} / \mathrm{ON})$. Thus, BASKET BALL FETCH required Ake to take the ball to the side of (beside) the basket, whereas BASKET BALL IN required her to place the ball inside the basket. Ake understood these different requirements well and rarely made an error to the relational term. Although Kako suggests testing Ake's ability to learn to discriminate between PUT IN and PUT ON, it is arguable that such understanding already exists within the terms FETCH and IN. Although an explicit prepositional particle is not present, the terms FETCH and IN contain implicit prepositions in that they code for location, especially if the presence of two object names (e.g., DT) already implies a general transport action.

It might also be argued that $\mathrm{IN}$ is itself a closed-class item, in that it describes a relationship and not a singular action. The set of words describing qualitatively expressed spatial relationships between two objects (e.g., in, under, beside, above) would seem to constitute a relatively small closed set. A similar argument as that for $\mathrm{N}$ might be made for FETCH, which could be glossed as "beside" rather than "take to."

It is questionable what would be added to Ake's language linguistically by using a particular verb followed by one or another preposition, as suggested by Kako (1999). Unless that verb was contrasted with another verb that also takes the same prepositions, the verb would be redundant, without unique semantic value. Thus, if we had used, say, BASKET BALL PUT FETCH or BASKET BALL PUT IN, instead of just FETCH or IN, PUT would be redundant, at best simply signaling the occurrence of the explicit 
prepositions FETCH (= beside) and IN (= into). However, if forms such as BASKET BALL TAKE FETCH (take the ball that is next to the basket) and BASKET BALL TAKE IN (take the ball that is in the basket) could be taught as a contrast, PUT would no longer be redundant, and understanding of a preposition could be more validly studied.

We have also explored Ake's understanding of the conjunction AND, signified by a newly introduced unique gesture (Prince, 1993). To test whether AND was semantically processed, and not simply a redundant stimulus, it was contrasted with a second familiar gesture, ERASE (Herman et al., 1984). ERASE directed the dolphin to ignore (disregard) all the preceding gestural commands. The syntactic frame used was Object $_{1}+$ conjunctive term + Object $_{2}+$ action term. Thus, BALL AND HOOP OVER required Ake to jump over both named objects, whereas BALL ERASE HOOP OVER required Ake to jump over the hoop only. An earlier study with Ake (Herman, Kuczaj, \& Holder, 1993) showed that anomalous sequences consisting of Object $_{1}+$ Object $_{2}+$ action (e.g., BALL HOOP OVER) most often resulted in a response to one object only, and next often a rejection. There were no responses to two objects. Hence, for the first time, AND set the occasion for a singular response to two objects.

Initial training emphasized familiarizing Ake with the AND gesture and exploring a variety of its potential uses, such as conjoined action terms (e.g., UNDER AND TAILTOUCH) or conjoined object + action sequences (e.g., HOOP UNDER AND BALL TAIL-TOUCH). Training on the two final

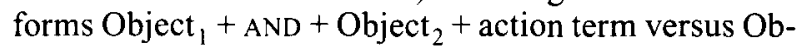
ject $_{1}+$ ERASE + Object $_{2}$ + action followed these preliminary explorations and were contrasted over 48 sessions before a final formal test was carried out. The test consisted of 60 trials given over 3 sessions of 20 trials each. There were 12 trials each of the two forms Object $_{1}+$ AND + Object $_{2}+$ action and Object 1 + ERASE + Object $_{2}+$ action. In addition, there were 12 relational trials Object ${ }_{1}$ + Object $_{2}$ + FETCH (e.g., BALL HOOP FETCH Or HOOP BALL FETCH), 12 simple object + action trials (e.g., BALL OVER), and 12 simple ERASE trials (e.g., BALL ERASE). Each 20 trial session presented 4 trials of each type in a quasirandom sequence. During each trial, two objects having names in the gestural language were present, floating freely about the tank; the particular pair used was changed every 10 trials. The results were: 10 correct responses (out of 12 possible) to the AND trials, 11 correct to the conjunctive-ERASE trials, 11 correct to the relational trials, 10 correct to the object-action trials, and all 12 correct to the simple ERASE trials. Although establishing proficiency in the conjunctive response required effort, it is clear that Ake became highly efficient in its use under the conditions described. Although categorizing FETCH and IN as function words is debatable, there is little doubt that AND, ERASE, and the indicative gesture can be so classified.

Locatives: "Left" and "right" possess closed-class functionality. Kako (1999) describes our evidence on novel relational sequences using locative-like items, such as FRISBEE FETCH UNDER HOOP, as a conjoined sentence, rather than parsing UNDER as a closed-class item. We agree with this interpretation. However, in addition to the implicit functionality of words such as iN, as described above, the concepts left and right can be considered discrete elements with the functional properties of closed-class items. For example, consider a sequence such as LEFT FRISBEE BASKET FETCH, an instruction to take the basket, which may be anywhere in the tank, to the Frisbee. The Frisbee was to the dolphin's left as she received the instruction from her trainer, and another Frisbee was to her right.

When the dolphin arrives at the basket, she may be anywhere spatially relative to the left Frisbee, and the vector from the transported object to her destination may be to her left, to her right, anterior, or posterior to her. Her excellent performance in arriving at the left object, regardless of the actual path taken, argues against LEFT and FETCH being conjoined actions - that is, go to the basket and go left. Instead, LEFT (or RIGHT) is encoded as a locative, a spatial representation that includes the objects at that location. Evidence for category-based rules is Ake's use of a precedence rule to interpret "left" in a sequence such as FRISBEE LEFT BASKET FETCH, by attaching LEFT to the object following it rather than to the object preceding it. Hence, LEFT and RIGHT have functional roles similar to locatives and are independent and nonredundant informational units.

\section{Concluding Remarks}

The evidence for syntactic competency in three very different species underscores the reality that such competencies are not the exclusive province of animals having a close evolutionary relationship to humans. There has often been an assumption that language-like skills must lie exclusively within the hominoid branch of evolution and that, to understand the evolution of human language, we must necessarily restrict our investigations to phylogenetically close lines of descent. This assumption has worked to the detriment of a fuller understanding of language skills and their foundations. For example, the quotation from Savage-Rumbaugh et al. (1993), cited by Kako (1999), refers to "the inherent similarity between ape and human brains" that contributes to the development of complex systems such as language. In fact, one might argue that, in terms of brain size, extent of cortical area, and brain-body relationships, there is more structural similarity of dolphin brain to human brain than of ape to human. Of course, this is an oversimplification.

However, to ignore the considerable capabilities of dolphins for complex information processing diverts attention from general cognitive processes that could in common explain dolphin and ape capabilities for syntactic processing, as well as other language-like or cognitively complex skills (Herman, 1980; Herman, Pack, \& MorrelSamuels, 1993). Much of human language skill has a 
cognitive component, such as class concepts for objects, sequential processing, and reference. The animal language work can help us to identify with more surety those processes in humans that may derive from general cognitive structures rather than from language-specific structures.

Dolphins live in a highly complex social world (see, e.g., Connor, Mann, Tyack, \& Whitehead, 1998) in which communication among members of the society and the formation of alliances and coalitions play a vital role in the development, well-being, and survival of individuals. There is much to learn in that social world (Herman, 1991). The evolution of advanced cognitive skills in dolphins that enable their demonstrated competencies in language-like tasks may largely result from the considerable advantages of social living, social learning, and social communication. The same may be true for chimpanzees and humans.

\section{REFERENCES}

BATES, E. (1993). Commentary on "Language comprehension in ape and child." Monographs of the Society for Research in Child Development, 58 (Serial No. 233), 222-242.

BloOM, L., LightBrown, P., \& Hood, L. (1975). Structure and variation in child language. Monographs of the Society for Research in Child Development, 40 (Serial No. 160).

Connor, R. C., Mann, J., Tyack, P. L., \& Whitehead, H. (1998). Social evolution in toothed whales. Trends in Ecology \& Evolution, 13, 228-232.

Fraser, C., Beluggi, U., \& Brown, R. (1963). Control of grammar in imitation, comprehension, and production. Journal of Verbal Learning \& Verbal Behavior, 2, 121-135.

GARDNER, B. T., \& GARDNER, R. A. (1971). Two-way communication with an infant chimpanzee. In A. M. Schrier \& F. Stollnitz (Eds.), Behavior of nonhuman primates (pp. 117-184). New York: Academic Press.

GARDNER, B. T., \& GARDNER, R. A. (1975). Evidence for sentence constituents in the early utterances of child and chimpanzee. Journal of Experimental Psychology: General, 104, 244-267.

HeRman, L. M. (1980). Cognitive characteristics of dolphins. In L. M. Herman (Ed.), Cetacean behavior: Mechanisms and functions (pp. 363429). New York: Wiley Interscience.

HERMAN, L. M. (1987). Receptive competencies of language trained animals. In J. S. Rosenblatt, C. Beer, M. C. Busnel, \& P. J. B. Slater (Eds.), Advances in the study of behavior (Vol. 17, pp. 1-60). Petaluma, CA: Academic Press.

Herman, L. M. (1991). What the dolphin knows, or might know, in its natural world. In K. Pryor \& K. S. Norris (Eds.), Dolphin societies: Discoveries and puzzles (pp. 349-364). Los Angeles: University of California Press.

Herman, L. M., KuczaJ, S., II, \& Holder, M. D. (1993). Responses to anomalous gestural sequences by a language-trained dolphin: Evidence for processing of semantic relations and syntactic information. Journal of Experimental Psychology: General, 122, 184-194.

Herman, L. M., \& Morrel-Samuels, P. (1990). Knowledge acquisition and asymmetries between language comprehension and production: Dolphins and apes as a general model for animals. In M. Bekoff \& D. Jamieson (Eds.), Interpretation and explanation in the study of behavior: Vol. I. Interpretation, intentionality, and communication (pp. 283-312). Boulder, CO: Westview.

Herman, L. M., Pack A. A., \& Morrel-Samuels, P. (1993). Representational and conceptual skills of dolphins. In H. R. Roitblat, L. M. Herman, \& P. Nachtigall (Eds.), Language and communication: Comparative perspectives (pp. 273-298). Hillsdale, $\mathrm{NJ}$ : Erlbaum.

Herman, L. M., Richards, D. G., \& Wolz, J. P. (1984). Comprehension of sentences by bottlenosed dolphins. Cognition, 16, 129-219.
Holder, M. D., Herman, L. M., \& KuczaJ, S., II (1993). A bottlenosed dolphin's responses to anomalous gestural sequences expressed within an artificial gestural language. In H. R. Roitblat, L. M. Herman, \& P. Nachtigall (Eds.), Language and communication: Comparative perspectives (pp. 299-308). Hillsdale, NJ: Erlbaum.

HURFORD, J. R. (1991). The evolution of the critical period for language acquisition. Cognition, 40, 159-201.

INGRAM, D. (1989). First language acquisition: Method, description and explanation. New York: Cambridge University Press.

KaKo, E. (1999). Elements of syntax in the systems of three languagetrained animals. Animal Learning \& Behavior, 27, 1-14.

Patterson, F. G. (1978). The gestures of a gorilla: Language acquisition in another pongid. Brain \& Language, 5, 72-97.

Petitto, L. A., \& Seidenberg, M. S. (1979). On the evidence for linguistic abilities in signing apes. Brain \& Language, 8, 162-183.

Povineli, D. J., \& Davis, D. R. (1994). Differences between chimpanzees (Pan troglodytes) and humans (Homo sapiens) in the resting state of the finger: Implications for pointing. Journal of Comparative Psychology, 108, 134-139.

PremaCk, D. (1976). Intelligence in ape and man. Hillsdale, NJ: Erlbaum.

PrINCE, C. G. (1993). Conjunctive rule comprehension in a bottlenosed dolphin. Unpublished master's thesis, University of Hawaii, Honolulu.

Richards, D. G., Wolz, J. P., \& Herman, L. M. (1984). Vocal mimicry of computer generated sounds and vocal labeling of objects by a bottlenosed dolphin, Tursiops truncatus. Journal of Comparative Psychology, 98, 10-28.

Ristau, C. A., \& Robins, D. (1982). Language in the great apes: A critical review. In J. S. Rosenblatt, R. B. Hinde, C. Beer, \& M. C. Busnel (Eds.), Advances in the study of behavior (Vol. 12, pp. 141-255). New York: Academic Press.

Rumbaugh, D. H. (1977). Language learning by a chimpanzee: The Lana project. New York: Academic Press.

SAVAGE-Rumbaugh, E. S. (1986). Ape language: From conditioned response to symbol. New York: Columbia University Press.

Savage-Rumbaugh, E. S., Murphy, J., Sevcik, R. A., Brakke, K. E., Williams, S. L. \& RuMBaUGH, D. (1993). Language comprehension in ape and child. Monographs of the Society for Research in Child Development, 58 (Serial No. 233), 1-221.

Savage-Rumbaugh, E. S., Rumbaugh, D. M., \& Boysen, S. (1980). Do apes use language? American Scientist, 68, 49-61.

SevciK, R. A., \& SaVAGE-Rumbaugh, E. S. (1994). Language comprehension and use by great apes. Language \& Communication, 14, 37-58.

Strohner, H., \& NELSON, K. E. (1974). The young child's development of sentence comprehension: Influence of event probability, nonverbal context, syntactic form, and strategies. Child Development, $\mathbf{4 5}$, 567-576.

Terrace H. S., Petitto, L. A., Sanders, R. J., \& Bever, T. G. (1979). Can an ape create a sentence? Science, 200, 891-902.

Thompson, C. R., \& Church, R. M. (1980). An explanation of language in a chimpanzee. Science, 208, 313-314.

WINITZ, H. (ED.) (1981). The comprehension approach to foreign language instruction. Rowley, MA: Newbury House.

XITCO, M. J., JR., \& RoITBLAT, H. L. (1996). Object recognition through eavesdropping: Passive echolocation in bottlenose dolphins. Animal Learning \& Behavior, 24, 355-365.

\section{NOTES}

1. Second-language (L2) learning may be a better model for animal language learning than is early first-language (L1) acquisition. L2 learning typically occurs after the sensitive period for Ll learning (Hurford, 1991) and therefore relies more on general cognitive mechanisms than on any language-specific mechanisms.

2. The symbol "D", as used by Kako, was notated as "S" by Herman, Kuczaj, \& Holder (1993) and by Holder et al. (1993), to indicate that the object was stationary (i.e., nontransportable). Examples of such objects are the other dolphin (PHOENIX), a stream of water entering the tank (WATER), and an underwater speaker suspended from the side of the tank (SPEAKER). This distinction is important because objects notated as $T$, 
for transport objects, can also serve as destination objects, depending on their syntactic position in the string.

3. The interpretations of our results may be more complex than singular application of Kako's (1999) properties, because animals may be operating on all aspects of the string. For example, as we discuss in this essay, with sentences of the form DTR, the relational FETCH or IN can be shown to possess qualities of open-class items, specifically verbs, which mediate the argument structure, as well as properties of closed- class items (prepositions), particularly if the DT word order alone is sufficient to code the overall verb-class action. The conclusion remains, however, that the grammatical categories of Ake's sentence items code for different functions, and interact with one another differently, depending on their syntactic position.

4. In addition to her knowledge of an acoustically based language, Phoenix also understands all of the gestural action words (verbs) used in Ake's language. 